\title{
Fast Gate: Subnanosecond Gated Detectors for Laser Radiography
}

J. Trebes, M. Feit, S. Hatchett, M. Key, M. Perry, T. Phillips, J. Sefcik, R. Snavely, M. Weber

February 25, 2000

U.S. Department of Energy

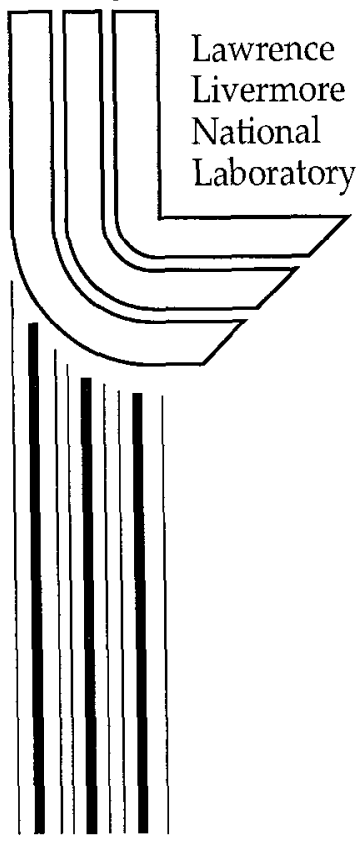




\section{DISCLAIMER}

This document was prepared as an account of work sponsored by an agency of the United States Government. Neither the United States Government nor the University of California nor any of their employees, makes any warranty, express or implied, or assumes any legal liability or responsibility for the accuracy, completeness, or usefulness of any information, apparatus, product, or process disclosed, or represents that its use would not infringe privately owned rights. Reference herein to any specific commercial product, process, or service by trade name, trademark, manufacturer, or otherwise, does not necessarily constitute or imply its endorsement, recommendation, or favoring by the United States Government or the University of California. The views and opinions of authors expressed herein do not necessarily state or reflect those of the United States Government or the University of California, and shall not be used for advertising or product endorsement purposes.

Work performed under the auspices of the U.S. Department of Energy by the University of California Lawrence Livermore National Laboratory under Contract W-7405-Eng-48.

This report has been reproduced directly from the best available copy.

Available to DOE and DOE contractors from the Office of Scientific and Technical Information

P.O. Box 62, Oak Ridge, TN 37831

Prices available from (423) 576-8401

http://apollo.osti.gov/bridge/

Available to the public from the National Technical Information Service

U.S. Department of Commerce 5285 Port Royal Rd., Springfield, VA 22161 http://www.ntis.gov/

OR Lawrence Livermore National Laboratory Technical Information Department's Digital Library http://www.llnl.gov/tid/Library.html 
Fast Gate: Subnanosecond Gated Detectors for Laser Radiography

J. Trebes, M. Feit, S. Hatchett, M. Key, M. Perry, T. Phillips, J. Sefcik, R. Snavely, M. Weber

\section{9-ERD-035}

\section{Introduction}

$X$-ray radiography is used as a principal diagnostic in a wide range of hydrodynamic tests relevant to the weapons program and also for basic materials and equation-of-state science studies. The quality of the x-ray radiograph can be significantly degraded by the scattering of $x$-rays within the object and by components of the test system itself. Elimination of these scattered $x$-rays from the recorded images can either substantially improve the image contrast and signal-tonoise or allow smaller, lower-cost $x$-ray sources to be used. The scattered $x$-rays could be minimized through the use of a much shorter-duration $x$-ray pulse and a fast, gated detector. The short duration $x$-ray pulse and the fast gated detector allow detection of only those $x$-rays which pass through the object being radiographed. $X-$ rays which are the result of scattering have longer path lengths and take longer to reach the target. Most of these can be eliminated if the detector if gated off before they arrive at the detector. Until recently there were no sources of high energy $\mathrm{x}$-rays ( $1-10 \mathrm{MeV}$ ) with short duration (sub 100 picosecond) pulses. Now the Petawatt Laser Facility (ref 1 ) at Lawrence Livermore National Laboratory has been able to produce 0.1 rads at 1 meter of $\mathrm{MeV}$ energy $\mathrm{x}$-rays in 1-0 picoseconds. Efforts are underway to significantly increase this $x$-ray output. The combination of the existing shortduration, Petawatt-produced $x$-ray pulses and an $x$-ray detector with sub-100-ps gate times could eliminate most of the scattered $x$-rays from the radiograph image and allow highly improved radiography particularly for larger, high density test objects.

\section{High speed, high energy $x$-ray gated detector development}

Our goal in this project was to develop a new class of high-speed, high-energy $x$ ray detectors for flash-x-ray radiography applications. These detectors would have a detection time of 100 ps or less and would be sensitive to $x$-rays up to $10 \mathrm{MeV}$. We evaluated several detector concepts through detailed analysis and modeling. These included detectors based on Cherenkov emission, on resonance transistion radiation, and on the use of the electric fields produced by Compton electrons to provide a polarization rotation in a laser-probed electro-optic crystal. These detector concepts, while having the potential for sub-100-ps time response, were shown to have insufficient $\mathrm{x}$-ray detection sensitivity at $\mathrm{MeV} \mathrm{x}$-ray energies of interest.

We also investigated the use of high speed scintillator crystals combined with a gated detector for high speed detection of pulsed x-rays. The proposed system consists of an array of long, narrow scintillator crystals, a quartz relay lens, and a gated detector. Figure 1 shows the conceptual set-up with a single scintillator crystal element. X-rays incident on the scintillator crystal array generate visible and ultraviolet photons through fluorescence. Each crystal functions as a single pixel for the $\mathrm{x}$-ray detector. These fluorescent photons are contained within the crystal by reflective metal coatings on the crystal walls. The photons travel down the crystal 
and emerge at the end where they are imaged with a quartz lens onto a gated microchannel plate detector. The gated microchannel plate detector can be gated on and then off in 100 picoseconds or less. The output of the gated microchannel plate is then proximity focused onto a CCD for read-out onto a computer.

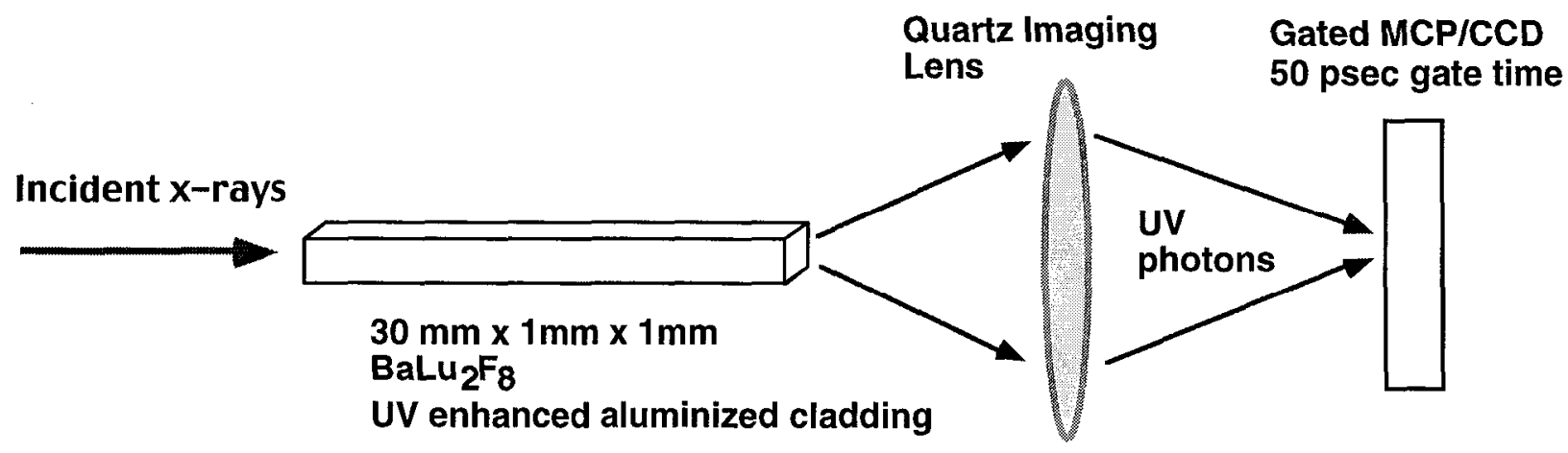

Figure 1. Conceptual gated, high energy $x$-ray system showing scintillator detector element for converting x-rays to ultraviolet light, relay lens, and gated detector.

The key to this approach is to have a scintillator crystal that is long enough and high enough in density to stop the high energy $x$-rays while still being short enough so that transit time effects in the long crystal do not limit the fast time resolution possible with the fluorescent photons. The width of the crystal needs to be small enough so that millimeter scale size spatial resolution can be obtained, but large enough so that side scatter from the incident $x$-rays do not travel between adjacent crystals. Cross talk by ultraviolet fluorescent photons is eliminated by coating the sides with aluminum. The most important property of the scintillator crystal is the time response of the fluorescence emission produced by the incident $x$-rays. Whilc the gated detector can limit the detection time to 50 picoseconds, if the decay time for emission of the fluorescent photons is slow only a small number of emitted photons will be within the detection time window significantly limiting the detection efficiency.

Recently the Delft group (ref. 2) reported a new crystal material barium lutetium floride $\left(\mathrm{BaLu}_{2} \mathrm{~F}_{8}\right)$ with sub-nanosecond ultraviolet fluorescence decay times. This crystal has a high density of $7.14 \mathrm{~g} / \mathrm{cm}^{3}$ allowing for good $\mathrm{x}$-ray stopping power at high $x$-ray energies and for submillimeter spatial resolution. Crystals of $\mathrm{BaLu}_{2} \mathrm{~F}_{8}$ could potentially be used for high speed, high energy x-ray detection if crystals of sufficient length could be manufactured.

We conducted Monte Carlo simulations to determine the optimal length and width for these crystals. For $5 \mathrm{MeV}$ x-rays most of the energy was deposited within a $3 \mathrm{~cm}$ length. Deposited energy from side scattered $x$-rays and electrons was contained within a transverse dimension of $1 \mathrm{~mm}$. We worked with a commercial company (AC Materials, Inc., Winter Park, FL.) to manufacture the first long crystal samples of $\mathrm{BaLu}_{2} \mathrm{~F}_{8}$. Sample crystals are shown in Figure 2. 


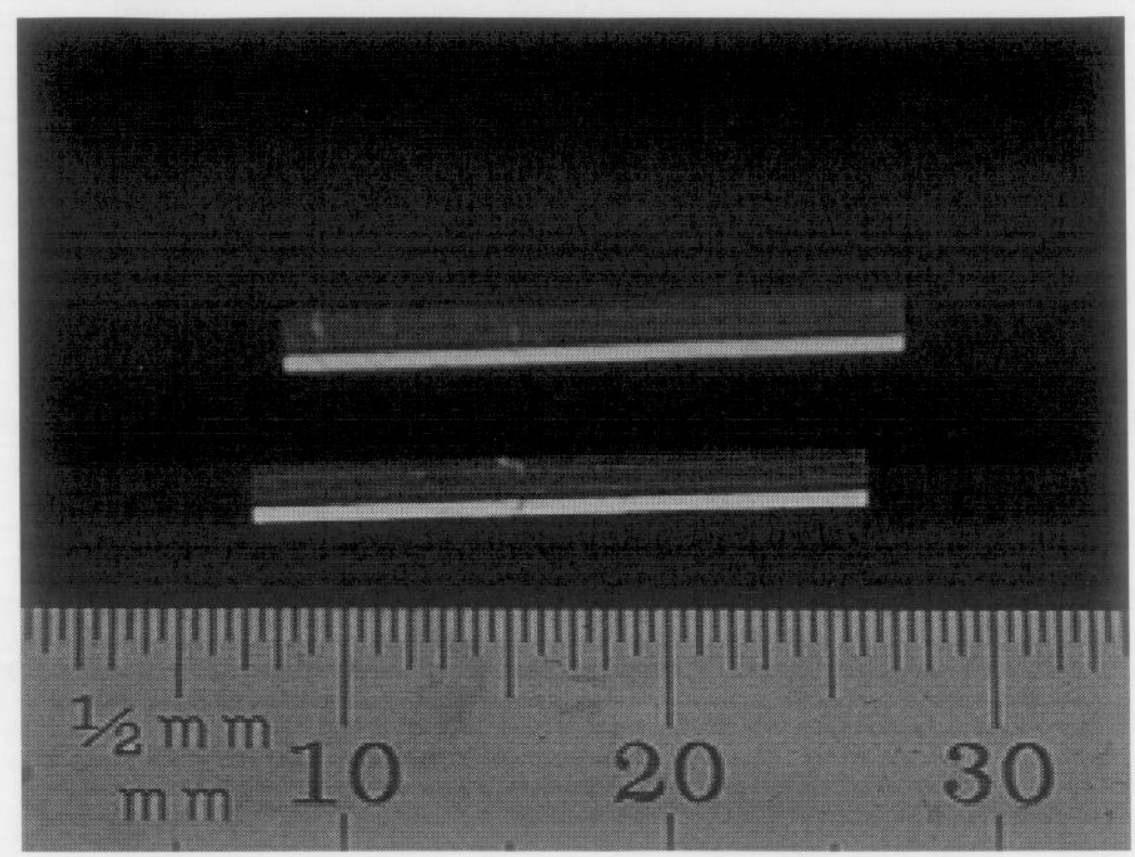

Figure 2. Barium lutetium floride crystals with $1 \mathrm{~mm}$ widths and $20 \mathrm{~mm}$ lengths.

We measured the scintillation intensities and fluorescence time properties of the barium lutetium floride crystals. Barium floride $\left(\mathrm{BaF}_{2}\right)$, a common $\mathrm{x}$-ray scintillator, was used a a reference for comparison. The measurements were made using a laser plasma pulsed x-ray source at the Lawrence Berkeley Laboratory. This source produces broad band x-rays with a mean energy of $18.7 \mathrm{KeV}$ and a pulse duration of 90 picoseconds. A 500 micron thick aluminum window was used to filter out low energy x-rays.

Single crystals of $\mathrm{BaF}_{2}$ were obtained from Bicron and of $\mathrm{BaLu}_{2} \mathrm{~F}_{8}$ from $\mathrm{AC}$ Materials, $1 \times 1 \times 10-\mathrm{mm}$ samples were prepared at LLNL. The peak luminosity and the luminosity for the first $160 \mathrm{~ns}$ after irradation with an x-ray pulse were measured. Three samples of each material were measured alternatively for time periods of 1050 seconds. The relative averages are reported in Table I.

There is eight-fold equidistant fluorine coordination of barium in cubic $\mathrm{BaF}_{2}$ whereas there is.ten-fold non-equidistant fluorine coordination in monoclinic $\mathrm{BaLu}_{2} \mathrm{~F}_{8}$. The decay times of the core valance luminescence (CVL) of the two materials are very similar, however because the $\mathrm{Ba}$ cation percentage in $\mathrm{BaLu}_{2} \mathrm{~F}_{8}$ is only $1 / 3$ that in $\mathrm{BaF}_{2}$ the CVL intensity is less. The Delft group (ref 2) report a gamma-ray excited light yield of 350 photons/MeV measured over $0.5 \mu$ s and 400 photons/MeV measured over $10 \mu$ s for $\mathrm{BaLu}_{2} \mathrm{~F}_{8}$ versus 1400 photons $/ \mathrm{MeV}$ for $\mathrm{BaF}_{2}$. This corresponds to relative light yields of $0.25-0.29$ for these time intervals and is in general agreement with the results in the final column of Table I obtained over $0.16 \mu$ s. 
Table I Properties of $\mathrm{BaF}_{2}$ and $\mathrm{BaLu}_{2} \mathrm{~F}_{8}$ at $300 \mathrm{~K}$

\begin{tabular}{|c|c|c|c|c|c|c|}
\hline Material & $\begin{array}{l}\text { Density } \\
\left(\mathrm{g} / \mathrm{cm}^{3}\right)\end{array}$ & $\begin{array}{l}\text { Effective } \\
\text { atomic } \\
\text { number } \\
\end{array}$ & $\begin{array}{c}\text { Emission } \\
\text { wavelength } \\
(\mathrm{nm}) \\
\end{array}$ & $\begin{array}{c}\text { Decay } \\
\text { time } \\
\text { (ns) } \\
\end{array}$ & $\begin{array}{c}\text { Relative } \\
\text { luminosity } \\
\text { (peak) }\end{array}$ & $\begin{array}{c}\text { Relative } \\
\text { luminosity } \\
\text { (over } 0.16 \mu \mathrm{s}) \\
\end{array}$ \\
\hline \multirow[t]{3}{*}{$\mathrm{BaF}_{2}$} & 4.88 & 53 & 220 & 0.8 & & \\
\hline & & & & & 1.00 & 1.00 \\
\hline & & & 310 & 620 & & \\
\hline $\mathrm{BaLu}_{2} \mathrm{~F}_{8}$ & 7.14 & 63 & $300^{(a)}$ & 0.8 & 0.43 & 0.23 \\
\hline
\end{tabular}

(a) The Delft group report only a broad emission band extending from $\sim 200$ to $\sim 400 \mathrm{~nm}$ with a peak at $298 \mathrm{~nm}$.

Figure 3 shows a comparison of the normalized scintillation decay curves for $\mathrm{BaF}_{2}$ and $\mathrm{BaLu}_{2} \mathrm{~F}_{8}$. The decay consists of two components: a fast $(<1 \mathrm{~ns})$ component arising from a core-valence luminescence (CVL) due to the radiative recombination of an electron from the $\mathrm{F}^{-} 2 \mathrm{p}$-valence band with a hole in the $\mathrm{Ba}^{2+} 5 \mathrm{p}$-core band and a slower component arising from emission of a self trapped exciton (STE). The rise time of the CVL is $<30 \mathrm{ps}$, the time resolution of the apparatus; the actual rise time is estimated to be $<1$ ps. The decay of CVL generally exhibits little variation with temperature. A comparison of the much longer and weaker exciton decay components for the two materials is shown in Figure 4. The amplitude of this decay is much less in $\mathrm{BaLu}_{2} \mathrm{~F}_{8}$.
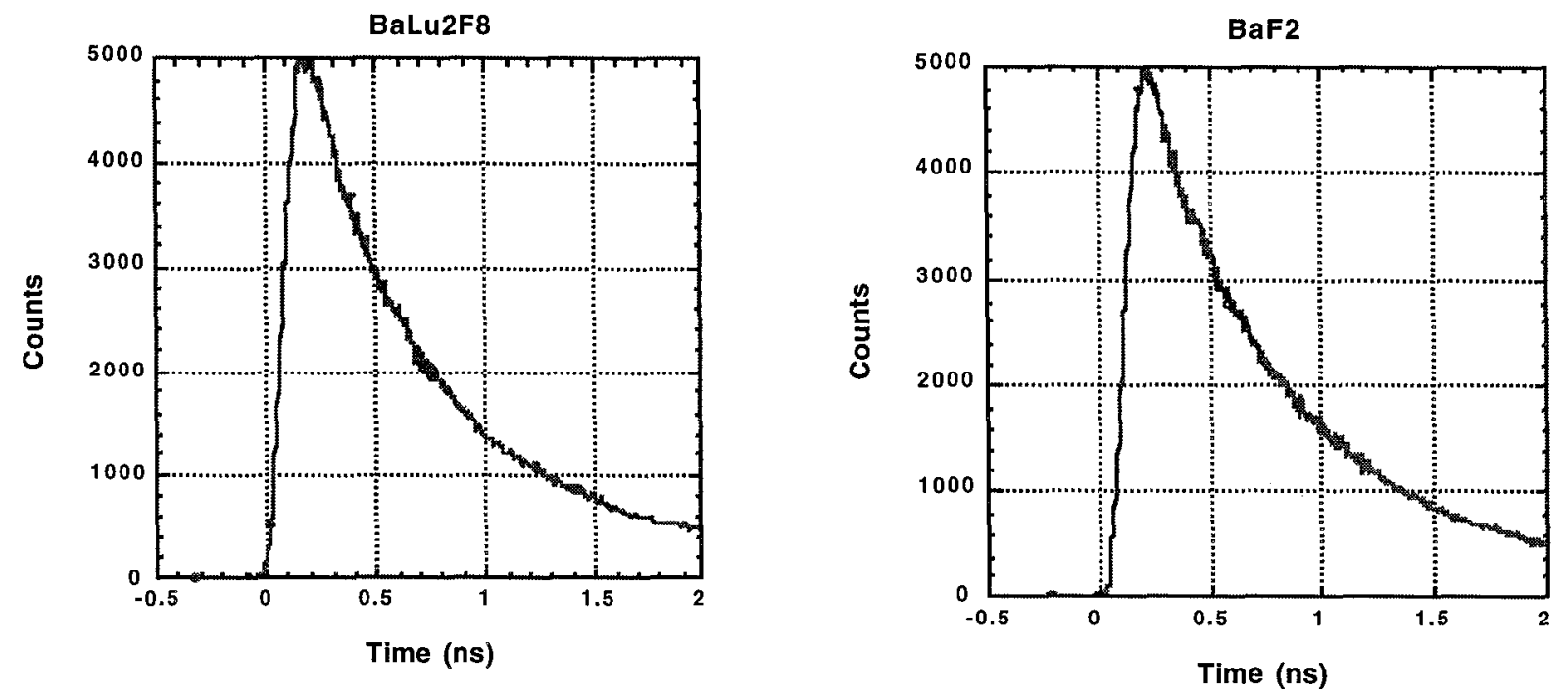

Figure 3. The comparison to the time histories of the fluorescence emission from $\mathrm{BaLu}_{2} \mathrm{~F}_{8}$ and $\mathrm{BaF}_{2}$. 

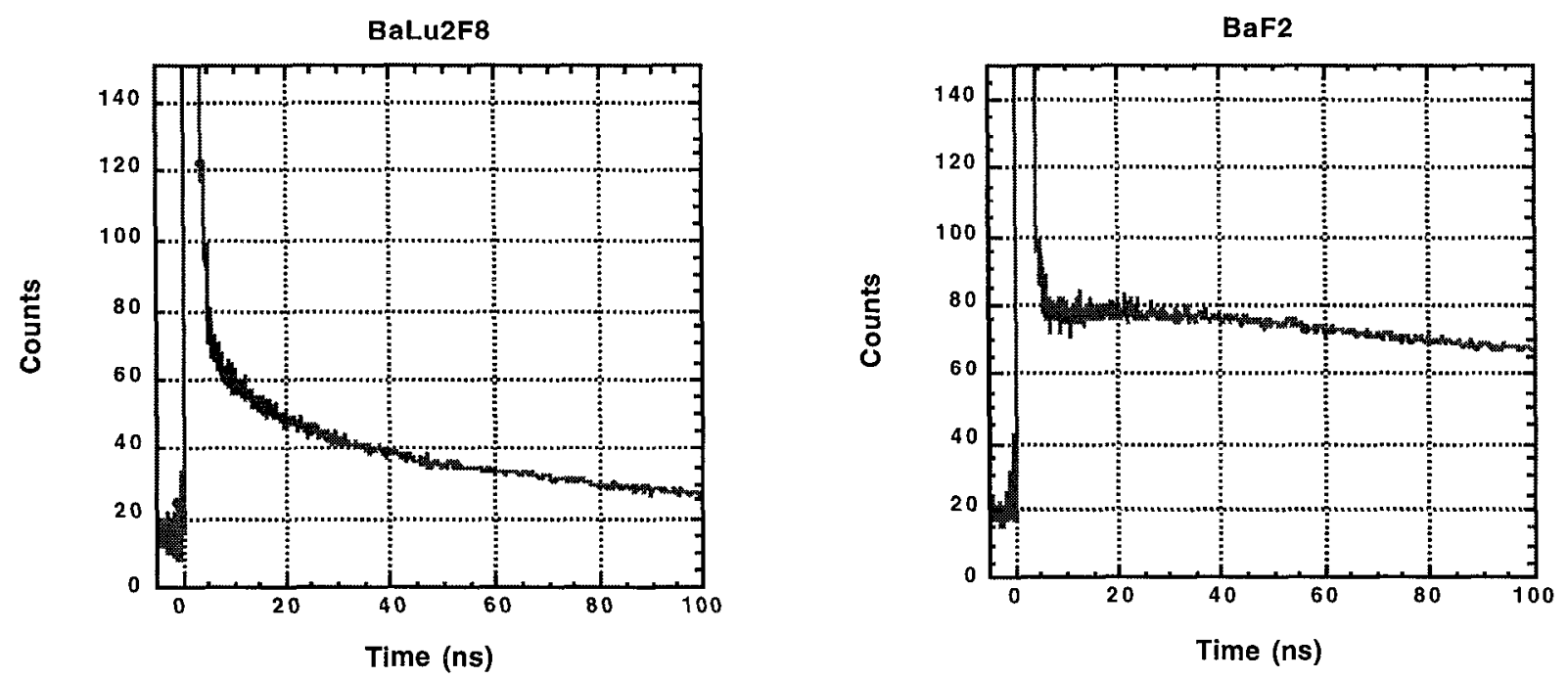

Figure 4. The comparison to the time histories of the fluorescence emission from $\mathrm{BaLu}_{2} \mathrm{~F}_{8}$ and $\mathrm{BaF}_{2}$ taken on a longer timescale. This shows the weaker long time scale emission from $\mathrm{BaLu}_{2} \mathrm{~F}_{8}$.

The measured fluorescence decay times show a rapid sub-nanosecond risetime with nanosecond decay times for the ultraviolet fluorescence emision. If an array of $\mathrm{BaLu}_{2} \mathrm{~F}_{8}$ crystals, each $30 \mathrm{~mm}$ in length and $1 \mathrm{~mm}$ wide were used as the $\mathrm{x}$-ray detector and the fluorescence emission were imaged onto a commercially available gated microchannel detector such as the system offered by LaVision with a 50 picosecond gate time, then a high efficiency, high speed, high energy x-ray detector could be developed for imaging applications. Using the fluorescence time histories and emission yields obtained in the measurements conducted at LBL we estimate that 10 microrads of $1 \mathrm{MeV}$ x-rays on a single would produce 33 ultraviolet photons/ 50 picoseconds/ microchannel plate detector pixel. This is more than sufficient to produce a detectable signal per image pixel since microchannel plate detectors have near single photon detection thresholds.

The time histories measured on the LBL laser plasma system were limited by the 90 picosecond time duration and the $18 \mathrm{KeV}$ mean energy. Determining the maximum detector efficiency required higher time resolution measurements of the fluorescence time response. To determine the performance of the $\mathrm{BaLu}_{2} \mathrm{~F}_{8}$ crystals under conditions more likely to be used in radiography applications and to improve the time resolution of the measurements, a test system was developed for use on the Lawrence Livermore National Laboratory Petawatt Laser.

A schematic of the detector test system developed for the Petawatt is shown in Figure 5. X-rays from a high $Z$ target are irradiated light pulses from the Petwatt laser. The resulting laser plasma emits $\mathrm{MeV}$ x-rays with 5-10 picosecond duration. 
The x-ray dose at the $\mathrm{BaLu}_{2} \mathrm{~F}_{8}$ crystal was $0.1 \mathrm{rad}$. The short pulse $\mathrm{x}$-ray irradiation produces fast ultraviolet fluorescence from the $\mathrm{BaLu}_{2} \mathrm{~F}_{8}$ crystal. This fluorescence is optically relayed to a streak camera detector with 20 picosecond time response. The predicted signal at the streak camera cathode would be 2000 photons/50 picoseconds/pixel. This is sufficient to produce a detectable signal and allow for a higher time resolution measurement of the fluorescence. The system was assembled at the Petawatt laser and a used on a number of $x$-ray producing target shots. Unfortunately streak camera timing issues and cathode problems prevented the acquisition of any useable time measurements of high speed ultraviolet fluorescence.

\section{Petawatt $x$-rays}

\section{1 rads}

\section{$2 \times 10^{8} \times$-rays $/ \mathrm{cm}^{2}$}

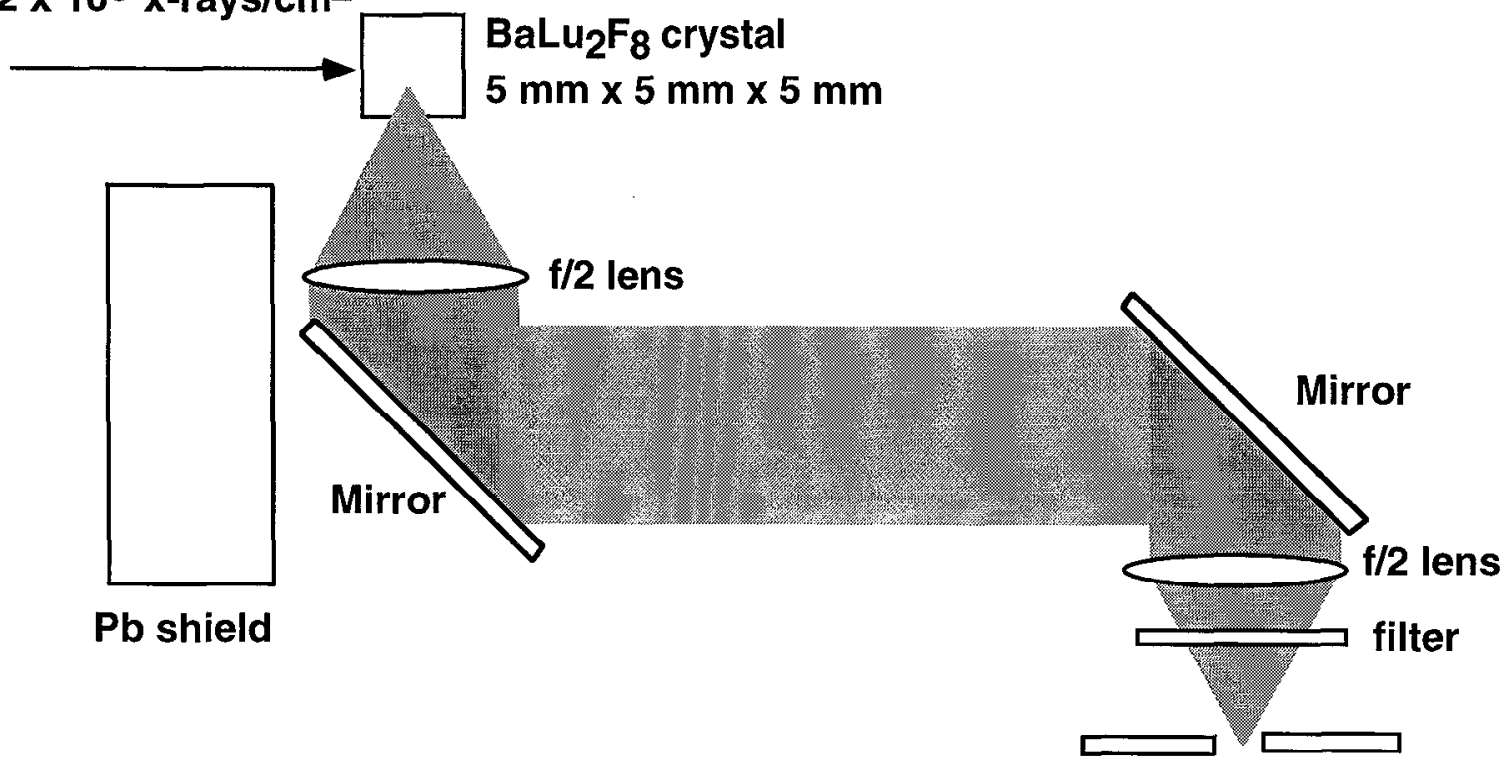

Streak camera slit

\section{Signal $\sim 2 \times 10^{3}$ uv photons/50ps/pixel}

Figure 5. The schematic of the fluorescence response time measurement system fielded on the Petawatt Laser to make accurate time measurements of the $\mathrm{BaLu}_{2} \mathrm{~F}_{8}$ crystal fluorescence under $x$-ray intensities, pulse durations, and energies appropriate for radiographic applications.

\section{Conclusion}

We investigated several approaches to the development of high speed, gated, high encrgy $x$-ray detection. $\Lambda$ system based on a fast scintillator was evaluated in detail. Scintillator crystals with appropriate geometry were manufactured for the first time 
and characterized. The measured times response and fluorescence efficiency was determined to be suitable for use in practical high energy $\mathrm{x}$-ray detectors.

\section{References}

1) "Petawatt laser pulses", M. D. Perry, D. M. Pennington, B. C. Stuart, J. A.

Britten, C. G. Brown, S. Herman, M. Kartz, J. Miller, H. T. Powell, G.

Tietbohl, M. Vergino, V. Yanovsky, V., Opt. Lett. 24, 160 (1999)

2)"Luminescence and scintillation propoerties of $\mathrm{BaY}_{2} \mathrm{~F}_{8}: \mathrm{Ce}^{3+}$ and of pure $\mathrm{Ce}^{3+}$ and doped $\mathrm{BaLuF}_{8}$., J. C. van't Spijker, et al., J. Luminescence, in press) 